\title{
Tracing the traveler's impact on the emergence of the SARS-CoV-2 cases in Gilgit-Baltistan, Pakistan
}

\author{
Bilqees Bano ${ }^{1}$, Tanveer Hussain ${ }^{2 *}$, Saba Mehmood $^{3}$, Ghulam Raza ${ }^{4}$, \\ Zakia Batool ${ }^{5}$ and Masooma ${ }^{6}$ \\ 1. Department of Biology, Virtual University of Pakistan, Rawalpindi-Pakistan \\ 2. Department of Molecular Biology, Virtual University of Pakistan, Lahore-Pakistan \\ 3. Combined Military Hospital, Gilgit, Gilgit-Baltitan-Pakistan \\ 4. Department of Biological Sciences, University of Baltistan, Skardu, Gilgit- Baltistan-Pakistan \\ 5. Department of Economics, NUML University of Pakistan, Islamabad-Pakistan \\ 6. Department of Education, Gilgit- Baltistan-Pakistan \\ *Corresponding author's email: tanveer.hussain@vu.edu.pk \\ Citation \\ Bilqees Bano, Tanveer Hussain, Saba Mehmood, Ghulam Raza, Zakia Batool and Masooma. Tracing the traveler's \\ impact on the emergence of the SARS-CoV-2 cases in Gilgit-Baltistan, Pakistan. Pure and Applied Biology.Vol. 10, \\ Issue 1, pp285-290. http://dx.doi.org/10.19045/bspab.2021.100030
}

\begin{tabular}{llll}
\hline \hline Received: 25/04/2020 & Revised: 31/08/2020 & Accepted: 02/09/2020 & Online First: 21/09/2020 \\
\hline \hline
\end{tabular}

\section{Abstract}

The SARS-CoV-2 outbreak in Wuhan, China surfaced in December of 2019 and then has been reported in almost all countries of the world. Pakistan is also one of these countries, vulnerable to this deadly virus. We evaluated the reported cases of SARS-CoV-2 in Gilgit-Baltistan Pakistan. We obtained recent daily case report from Provincial emergency operation centre Gilgit Baltistan to find the pattern of occurrence of new cases from the first disease case reported on $13^{\text {th }}$ March 2020 to the $6^{\text {th }}$ April 2020. We determined the Correlation between the susceptible travelers and infected positive cases. By finding the probability we found the travelers specifically Zaireen (pilgrims) contributed more in the disease transmission to the local persons than the travelers from other countries. In our study we found that SARS-CoV-2 is more common in males than females. The rate of recovery found greater than the rate of emergence of new cases. The pattern of daily new cases surfaced is unpredictable as it varies daily. We found p (probability) value is less than $5 \%$, we can say that there are 0.920 correlations between susceptible travelers and reported case, forecasting that travelers are the major source of the SARS-CoV-2 epidemic in GilgitBaltistan. We also found that overall, in Gilgit-Baltistan the SARS-CoV-2 cases rising disproportionately as compare to the other parts of Pakistan as sometime it rises because most of the Pilgrims arrived through Taftan belong to Gilgit-Baltistan.

Keywords: Epidemic; Pilgrims; SARS-CoV-2; Susceptible; Transmission

\section{Introduction}

In the context of an emerging pandemic novel corona virus disease, evaluating its spread among humans all over the world is the need of hour. The SARS-CoV-2 has penetrated more than two hundred and nine countries since it was surfaced in Wuhan,
China in December of 2019.By $11^{\text {th }}$ March 2020, the virus had penetrated to 113 countries and territories with 118,162 registered cases and death toll 4290 [1]. Patients of the deadly SARS-CoV-2 show varying symptoms of fever, cough, fatigue, 
shortness of breath, pneumonia, and other respiratory tract symptoms which in many cases lead to the death [2]. It has been observed that the incubation period of SARS-CoV-2 is not same and it varies among patients. In some patient it is approximately 3-7 days whereas in some other patient 14 days of incubation period has been observed [3]. SARS-CoV-2 is different from SARS in a way that it is infectious during incubation period when patients are asymptomatic [4]. After its surfacing and progression in China, World Health Organization (WHO) primarily named the virus, the 2019 novel corona virus (2019-nCoV). On 30 January 2020, WHO declared the SARS-CoV-2 as an epidemic. On $11^{\text {th }}$ February 2020, the WHO named the disease caused by SARS-CoV-2 as corona virus disease 2019 (COVID-19).

Numbers of the positive cases have been increasing all over Pakistan; currently Punjab and Sindh provinces are the epicenters of SARS-CoV-2 in Pakistan. Data produced by health departments of Pakistan shows that most of the patients have travel history, recently visited different countries across the world. There is high risk of rising in number of positive cases in Pakistan as it is situated between China and Iran, the two main epicenters ofSARS-CoV-2 .First two cases of SARS-CoV-2 in Pakistan surfaced in early March 2020, later it was confirmed that they were the pilgrims from Iran and on their return tested positive for the disease. Sindh and Punjab have had very strong epidemiological surveillance and have constantly shown high sensitivity of casedetection during the SARS-CoV-2 outbreak. Twenty cases with positive result were reported within 15 days, after confirming the first case of SARS-CoV-2 in Pakistan, including 14 cases in Sindh Province, 5 in Gilgit-Baltistan and 1 in Baluchistan [5]. It is believed that several infectious cases are still undocumented which is playing critical role in the spread of this deadly virus in the country. These unreported infected persons with unrecognizable symptoms are also the potential source of ambiguity for the data collection. It is necessary to prevent the spread of SARS-CoV-2 by adapting protective measures including wearing medical masks, taking adequate rest, and maintenance of social distancing [6].

On March 16, 2020, Gilgit-Baltistan daily situation report identified three positive cases of SARS-CoV-2 with clear symptoms during the screening of travelers from different countries amidst the its outbreak in China. The emergence of reported cases of SARS-CoV-2 in Gilgit-Baltistan is associated with the imported cases of patients having recent travel history during the outbreak of the disease. As most of the positive patients have been the travelers, the prevalence of SARS-CoV-2 was initially greater in travelers than the local residents. Some emergence of resident cases reported shows that the travelers are the main source of community transmission of this deadly disease. The quarantine measures are very critical to restrict the spread of diseases in the all over the world. This study is to find out the impact of travelers on the prevalence of the disease in all the districts of GilgitBaltistan. Differences in susceptibility of different age group and gender susceptibility were also observed in this study.

\section{Materials and Methods}

We obtained recent daily case reports from Provincial emergency operation centre (PEOC) Gilgit Baltistan to find the pattern of occurrence of new cases from the first disease case reported on $13^{\text {th }}$ March 2020 to the $6^{\text {th }}$ April 2020. We categorized imported cases of travelers as Zaireen; $77 \%$ (149 of 193), Tablighee; $2.5 \%$ (5 of 193), Umrah; $0.5 \%$ ( 1 of 193) and others; $1.0 \%$ (2of 193). $18.6 \%$ cases were locally transmitted by contact with the infected travelers. All the travelers were under surveillance for 14 days 
and were tested for SARS-CoV-2, whether they were symptomatic or asymptomatic, in local district hospital and district level CDCs. Better treatment facilities were made available to the patients and preventive measures were also taken by the patients. Symptomatic cases were isolated and treated at respective district hospitals. Asymptomatic positives were isolated at centralized facilities and monitored for 14 days. To analyze the relation between travelers and infected positive cases correlation was applied.

\section{Results}

As of the April 6, 2020, final clinical outcomes were known for 193 of the 1096 cases in Gilgit-Baltistan data; with three dead and 15 recovered. We observed approximately equal numbers of male (105 out of 193) and female cases (88 out of 193) $(45.6 \%$ vs. $54.4 \%)$ in the reported data. It is observed that the patients of age group 45$<60$ were more likely to be affected with $32.4 \%$ cases (Fig. 1). We found that the district Skardu has high susceptible 290 cases of all the districts of Gilgit-Baltistan, whereas the district with lowest susceptible cases was Hunza (0.36\%).District Nagar has more confirmed positive cases $(37.8 \%)$ than Skardu (25.4\%) (Fig. $2 \& 3$ ). Further, we analyzed the travelers contribution in the disease spread by analyzing the data of travelers in the three divisions of GilgitBaltistan (Fig. 4).We also predicted the recovery cases over reported cases by plotting the probability graph (Fig. 5).We also establish the pattern of daily new cases emergence by finding the correlation (Fig. $6)$. To show the relatedness of travelers to the outcome of infected cases, we found the correlation of $0.920(p=0.00015)$ between the susceptible travelers and positive cases.

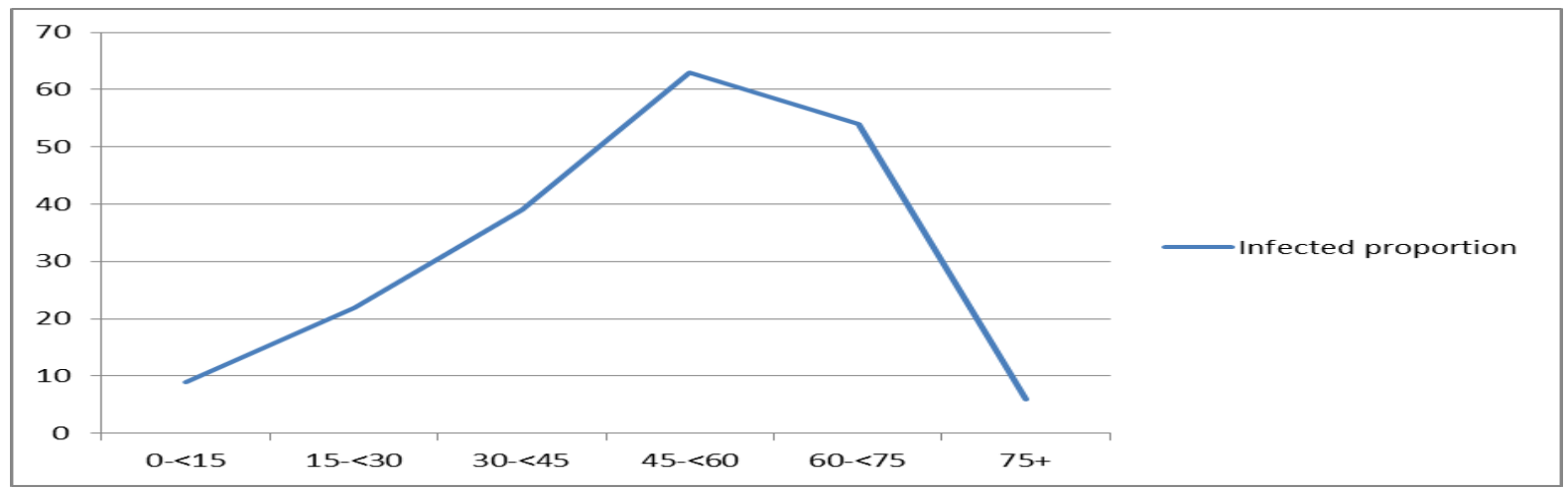

Figure 1. Proportion of confirmed cases of SARS-CoV-2 by age group in Gilgit-Baltistan

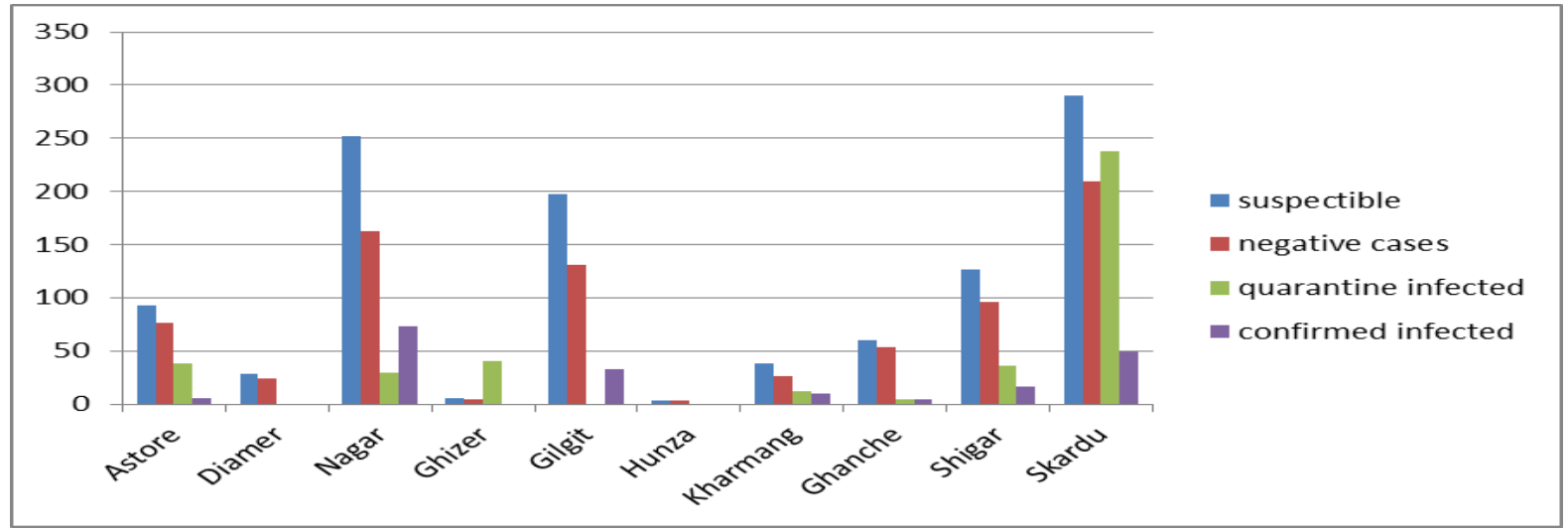

Figure 2. District wise trends in confirmed cases of SARS-CoV-2 in Gilgit-Baltistan 
Bano et al.

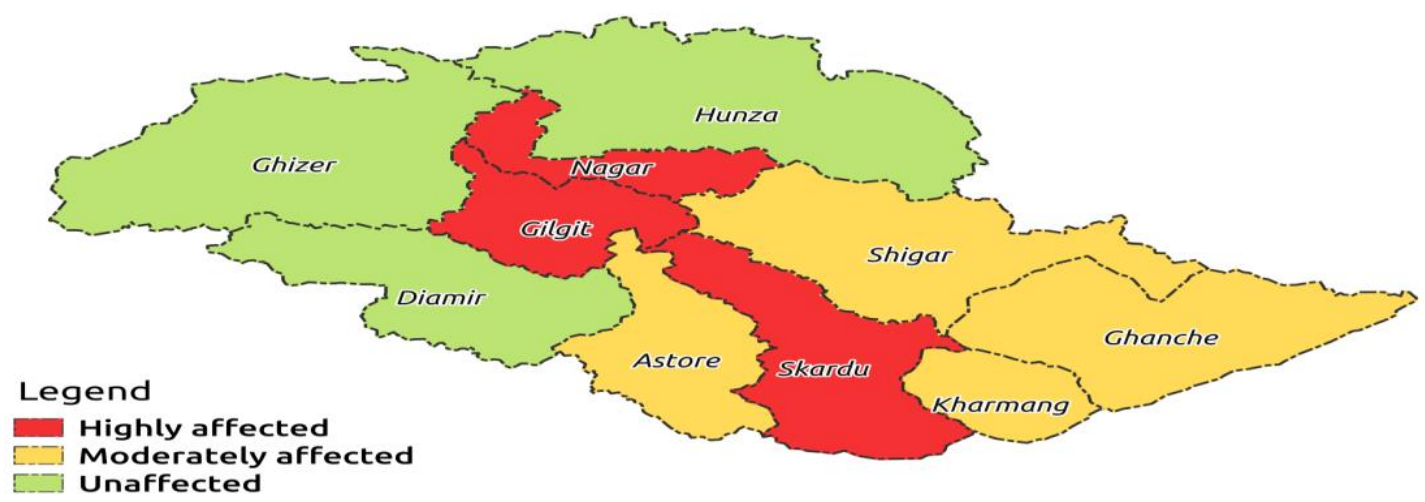

Figure 3. SARS-CoV-2 trends in all districts of Gilgit- Baltistan

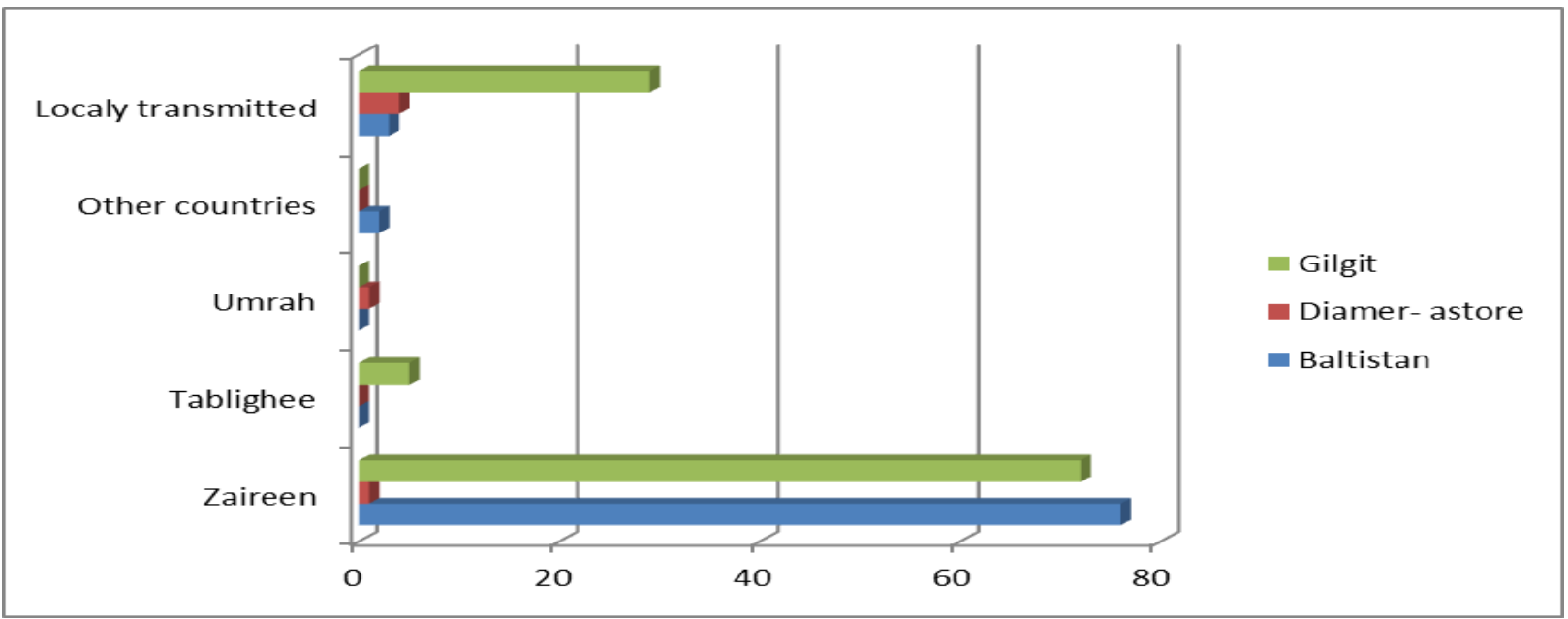

Figure 4. Infected travelers of different countries and local cases in the Gilgit-Baltistan divisions

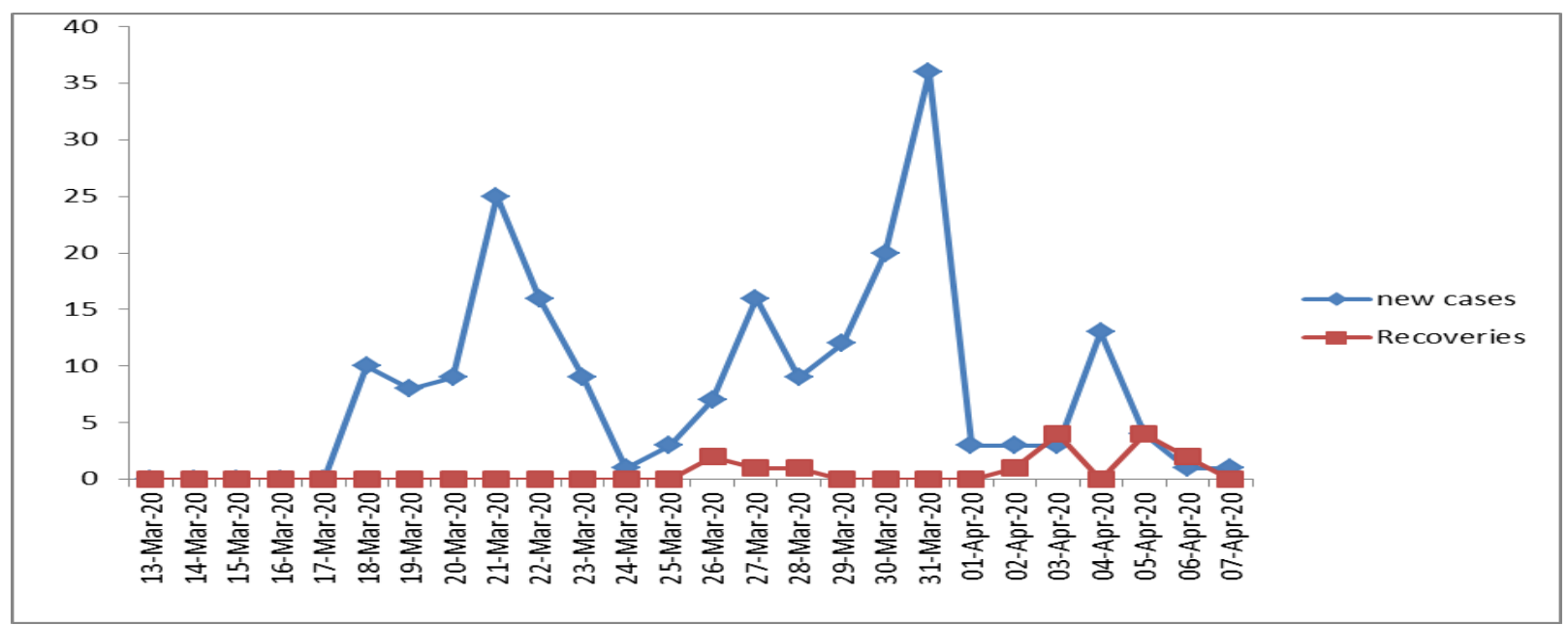

Figure 5. Prediction of new cases of SARS-CoV-2 Vs. recoveries in Gilgit-Baltistan from $1^{\text {th }}$ March 2020 to the $6^{\text {th }}$ April 2020 


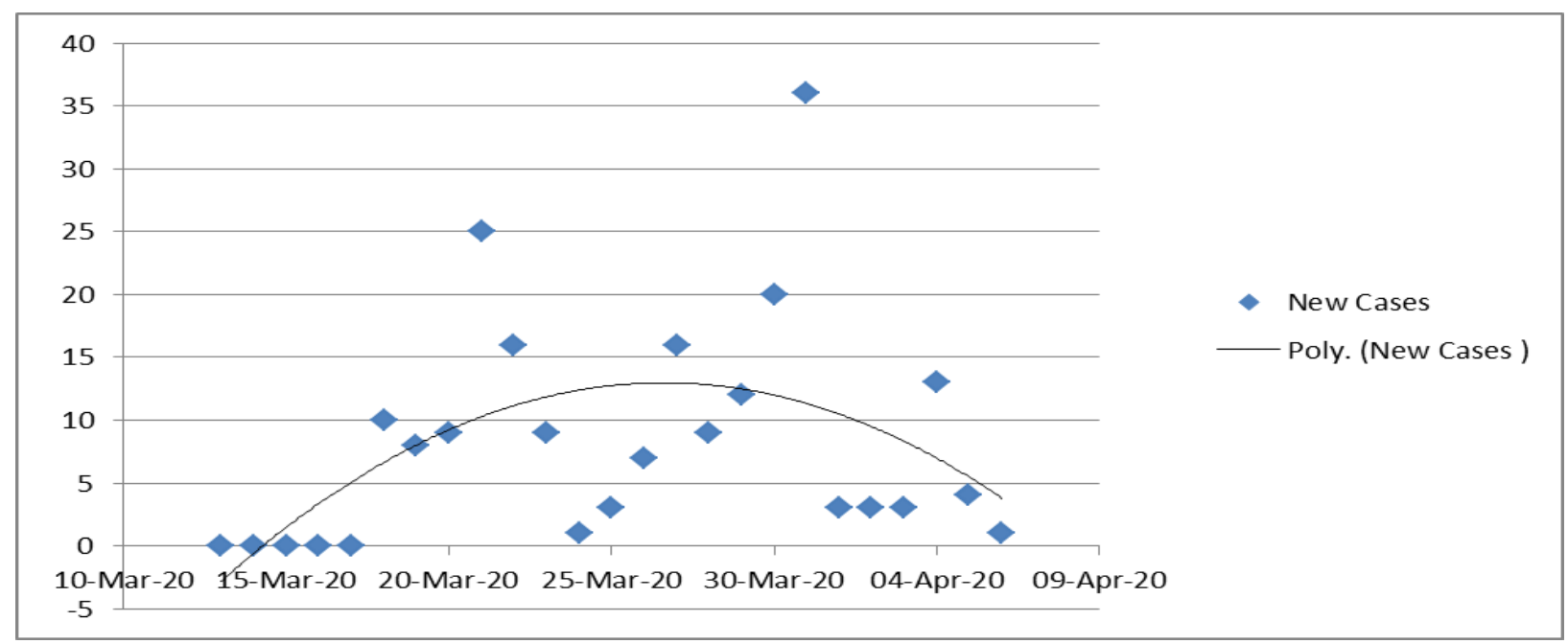

Figure 6. Pattern of new cases with the passage of time in Gilgit-Baltistan from $13^{\text {th }}$ March 2020 to the $6^{\text {th }}$ April 2020

\section{Discussion}

The analysis of SARS-CoV-2 cases reported in Gilgit-Baltistan provides information regarding transmission, prevalence and pattern of the spreading of the disease in Gilgit-Baltistan. By analyzing the data, we found more male cases than female in our study, apparently depicting that SARS-CoV2 is somewhat gender specific. Many studies suggest that men are more susceptible than women and it is due to sexbased immunological differences [2]. We observed that age of most of the patient's lies between 45 to 65 years. Age dependency was observed in susceptible infected patients in several cases [7]. This specific age group is more vulnerable to the SARS-CoV-2 virus because of low immune responses to the infection. Another study showed the mostly affected patients of 425 cases were of less than 60 years old and children were less vulnerable than all age groups [8]. Travelers from other countries, mainly pilgrims from Iran proved to be the greater cause of SARS-CoV-2 spread in this region. Pakistan started active screening of pilgrims from Iran after the emergence of confirmed imported cases of SARS-CoV-2 from Iran [9]. In many studies, it has been proved that travelling is one of the major causes of SARS-CoV-2 spread in the world. As a study in China, observed that rapid national and global spread of the virus was related to the largest annual human migration in their Spring Festival travel season [10]. So we can relate this to our study, as in our study the main cause of spread of the coronavirus in Skardu and Nagar were found to be due to pilgrims who travelled to Iran for the pilgrimage of holy sites located there. We found that the district Skardu has more susceptible cases of all the districts of Gilgit-Baltistan, although, district Nagar has more confirmed positive cases than Skardu, it is due to different factors like availability of treatment facilities and preventive measure taken by the patients. Overall, in Gilgit-Baltistan the SARS-CoV2 cases rising disproportionately as compare to the other regions of GB. It is because the residents of Gilgit-Baltistan demanded closure of the border earlier amidst its outbreak in other regions of Pakistan.

\section{Conclusion}

The main cause of emergence of infected cases is associated to the importation of the travelers from other countries during the time of outbreak. Hence the control of the 
sources of the disease will prove helpful to deal with deadly COVID-19 epidemic. Travel restriction must be implemented to reduce the spread of the disease in GilgitBaltistan. In order to control the spread of the disease, implementation of travel restriction, early diagnoses of the disease isolation and supportive treatments must be done.

\section{Authors' contributions}

Conceived and designed the experiments: $\mathrm{T}$ Hussain, Performed the experiments: B Bano, Analyzed the data: G Rasool, Z Batool, B Bano \& Masooma, Contributed materials/ analysis/ tools: $\mathrm{G}$ Rasool, $\mathrm{S}$ Mehmood \& Masooma, Wrote the paper: B Bano \& T Hussain.

\section{Acknowledgements}

The website of "COVID-19 Health Advisory Platform by Ministry of National Health Services Pakistan" is acknowledged for data along with Mr. Syed Mubasher Hussain Rizvi. Mr. Obaid ur Rehman from SUPARCO, Pakistan is acknowledged for helping us in map provision.

\section{References}

1. Novel corona virus (COVID-19) situation March 11, 2020. https://experience.arcgis.com/exp erience/685d0ace521648f8a5beeee1b9 $125 \mathrm{~cd}$.

2. Chen N, Zhou M, Dong X \& et al. (2020). Epidemiological and clinical characteristics of 99 cases of 2019 novel coronavirus pneumonia in Wuhan, China: a descriptive study. Lancet Epub 395: 507-513.

3. Wang C, Horby PW, Hayden FG \& Gao GF (2020). A novel coronavirus outbreak of global health concern. Lancet Epub 395: 470-473.

4. Yang, Yang Y, Lu Q \& et al. (2019). Epidemiological and clinical features of the 2019 novel coronavirus outbreak in China.

DOI:10.1101/2020.02.10.20021675.

5. COVID-19 live dashboard (Pakistan): National Institute of Health Islamabad.

6. Guan $\mathrm{W}, \mathrm{Ni} \mathrm{Z}, \mathrm{Hu} \mathrm{Y}$ \& et al. (2020). Clinical characteristics of 2019 novel coronavirus. New Engl J Med 382(18): 1708-1720.

7. Wu TJ, Leung K, Bushman M, Kishore $\mathrm{N}$, Niehus R, Pablo M, de-Salazar, Benjamin J, Cowling, Lipsitch M \&Leung MG (2020). Estimating clinical severity of COVID-19 from the transmission dynamics in Wuhan, China. Nat Med 26: 506-510.

8. Li Q, Guan X, Wu P \& et al. (2020). Early transmission dynamics in Wuhan, China, of novel coronavirus-infected pneumonia. New Engl J Med 382: 11991207

9. Pakistan 'concerned' over Iran coronavirus outbreak closes border. https://www.geo.tv/latest/27396 4-pakistan-alert. Accessed 6 Mar 2020.

10. Li Q, Zhao S, Gaod D, Loue Y, Yangf $\mathrm{S}$, Musae $\mathrm{S}$,Wang H.M, Caig $\mathrm{Y}$, Wangg W, Yangh L \& Hee D (2020). A conceptual model for the coronavirus disease 2019 (COVID-19) outbreak in Wuhan, China with individual reaction and governmental action. Int $J$ Infect Dis 9: 211-216. 